\title{
A PÁGINA ARRUMANDO LETRAS COMO UM ESPAÇO PARA A DESCONSTRUÇÃO dA dOMINAÇÃO dO PATRIARCADO
}

\author{
THE PAGE ARRUMANDO LETRAS AS SPACE FOR THE DECONSTRUCTION OF \\ PATRIARCHAL DOMINATION
}

LA PÁGINA ARRUMANDO LETRAS COMO UN ESPACIO PARA LA DESCONSTRUCCIÓN DE LA DOMINACIÓN DEL PATRIARCADO

Nathália Lima Romeiro ${ }^{1}$

Franciéle Carneiro Garcês da Silva ${ }^{1}$

Anna Cristina Caldeira de Andrada Sobral Brisola ${ }^{1}$

${ }^{1}$ Universidade Federal do Rio de Janeiro

Correspondência

${ }^{1}$ Nathália Lima Romeiro

Universidade Federal do Rio de Janeiro

Rio de Janeiro, RJ

E-mail: ntromeiro91@gmail.com

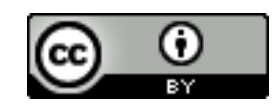

JITA: HT. Web 2.0, Social networks.

Submetido em: $24 / 05 / 2018$

Aceito em: 16/05/2018

Publicado em: 27/08/2018 
RESUMO: Este artigo se propõe a discutir a dominação patriarcal presente nas músicas populares discutidas e reescritas na página Arrumando Letras na mídia social Facebook, bem como a compreensão dos fenômenos, valores e costumes estudados pela ética, compreendida como a Ciência da moral. Os objetivos específicos incluem: a) verificar as contribuições bibliográficas no que tange ao arcabouço teórico e conceitual sobre ética; b) discutir por intermédio das postagens da página Arrumando Letras, a dominação patriarcal e masculina contra as mulheres presente nas músicas populares entre brasileiros e brasileiras; c) analisar a página Arrumando Letras como um importante espaço de militância e promoção de debate sobre respeito entre gêneros e herança de uma cultura patriarcal; d) Refletir como a competência crítica em informação é aplicada na página e como contribui com a formação dos seguidores da mesma. A fundamentação conceitual deste artigo discute e conceitua ética, moral, dominação patriarcal, dominação masculina e competência crítica em informação. A metodologia adotada foi de natureza exploratória de abordagem qualitativa com base na Análise de Redes Sociais (ARS). A partir dos resultados obtidos, refletimos e desejamos que cada vez mais a dominação patriarcal seja desconstruída, e seus danos na vida das mulheres erradicados à medida que o nosso protagonismo, bem como de outros gêneros, sejam cada vez mais representados, não só na Ciência da Informação, mas em outras ciências, na política, na educação e em diferentes contextos socioeconômicos e culturais.

PAlavraS-Chave: Ética. Patriarcado. Mídias sociais. Cultura musical. Gênero. Competência crítica em informação.

ABSTRACT: This article proposes to discuss the patriarchal domination present in the popular songs discussed and rewritten in the page Arrumando Letras in the social media Facebook, as well as an understanding of the phenomena, values and customs studied by ethics, as a Science of the moral. The objetcs especifics: a) verify as bibliographic contributions regarding the theoretical and conceptual framework on ethics; b) Discuss through the page posts Arrumando Letras, a male and patriarchal domination against women present in the popular songs between Brazilians and Brazilians; c) to analyze the page Arrumando Letras as an important space of militancy and promotion of debate about respect of genres and inheritance of a patriarchal culture; d) Reflect as critical competence in the information is applied on the page and how to contribute to the formation of the followers of the same. The conceptual foundation of this article approached and conceptualized ethics, morality, patriarchal domination, masculine domination and critical competence in information. The methodology adopted was an exploratory qualitative approach based on Social Network Analysis (SNA). From the results obtained, we reflect and wish that more and more patriarchal domination is deconstructed, and its damages in the lives of women eradicated as our protagonism, as well as other genres, are increasingly represented, not only in Science Information but in other sciences, in politics, in education and in different socioeconomic and cultural contexts.

KEYWORDS: Ethics. Patriarchate. Social media. Musical culture. Gender. Critical information literacy.

RESUMEN: Este artículo se propone discutir la dominación patriarcal presente en las canciones populares discutidas y reescritas en la página Arreglando Letras en los medios sociales Facebook, así como la comprensión de los fenómenos, valores y costumbres estudiados por la ética, comprendida como la Ciencia de la moral. Los objetivos específicos incluyen: a) verificar las contribuciones bibliográficas en lo que se refiere al marco teórico y conceptual sobre ética; b) discutir por intermedio de las posturas de la página Arrumando Letras, la dominación patriarcal y masculina contra las mujeres presente en las músicas populares entre brasileños y brasileñas; c) analizar la página Arreglando Letras como un importante espacio de militancia y promoción de debate sobre respeto entre géneros y herencia de una cultura patriarcal; d) Reflejar cómo la competencia crítica en información se aplica en la página y cómo contribuye a la formación de los seguidores de la misma. La fundamentación conceptual de este artículo discute y conceptualiza ética, moral, dominación patriarcal, dominación masculina y competencia crítica en información. La metodología adoptada fue de naturaleza exploratoria de abordaje cualitativo con base en el Análisis de Redes Sociales (ARS). A partir de los resultados obtenidos, reflejamos y deseamos que cada vez más la dominación patriarcal sea desconstruida, y sus daños en la vida de las mujeres erradicados a medida que nuestro protagonismo, así como de otros géneros, sean cada vez más representados, no sólo en la Ciencia de la Información pero en otras ciencias, en la política, en la educación y en diferentes contextos socioeconómicos y culturales.

Palabras Clave: Ética. Patriarcado. Redes sociales. Cultura musical. Género. Competencia crítica en información.

p. $317-337$

set./dez. 2018 


\section{INTRODUÇÃ̃o}

Atualmente, tem se popularizado nas mídias sociais (twitter, facebook, instagram) a militância feminista que visa a desconstrução de valores morais impostos às mulheres. Valores estes, que, na maioria dos casos, põe a mulher (cisgêneras, transgêneras, lésbicas, entre outras generalidades, contemplando as diferentes realidades de opressão étnico-raciais) em posição submissa frente à hegemonia imposta pela cultura patriarcal, sob a luz da ideologia burguesa capitalista, determinada, majoritariamente, por ideais de homens brancos conservadores, heterossexuais e de classe econômica abastada (SOUZA, 2013).

A desconstrução desses valores tem sido levantada nas mídias sociais através de postagens em diferentes páginas, comunidades e perfis, por meio de textos, vídeos e/ou imagens e tem como objetivo principal o empoderamento feminino, a reflexão e ação na luta pela igualdade de tratamento que visa o respeito entre os gêneros (binários e não-binários). Tal reflexão provocada por estas postagens e discussões contribuem para a formação de uma competência crítica em informação, na medida que estimulam a curiosidade, a busca por assuntos discutidos e o pensamento crítico e reflexivo em relação à realidade da opressão apontada pelo feminismo. A estrutura patriarcal, nesse contexto, também será analisada a fim de refletir o silenciamento da mulher e as opressões socialmente construídas que muito contribuíram para que não nos tornássemos protagonistas em diversas esferas sociais (arte, política, economia, direito, nas relações afetivas, etc.) que ao longo da história brasileira nos manteve à margem em relação aos homens com baixa representatividade nas esferas descritas.

Diante desta construção social, como as mulheres podem se posicionar e construir uma autoestima igualitária entre os gêneros quando a organização social foi montada por homens e, em muitos casos, para o favorecimento dos mesmos? As imposições morais contra as mulheres, ao longo do tempo, construíram valores e moldaram costumes (RIBEIRO, 2013). A partir de uma perspectiva cultural, utilizaremos os escritos de Aristóteles (1991) que, ao admitir que toda arte e toda investigação, bem como as ações e escolhas de uma pessoa, miram um bem qualquer, o filósofo mostra que tal bem pode moldar uma estrutura que muitos indivíduos tendem a seguir. Outra aproximação acadêmica necessária é a aproximação com os escritos de Bourdieu (2012) sobre a dominação masculina, que implica na maneira como os homens se comportam em relação às mulheres, numa estrutura em que eles encontram-se hierarquicamente no comando, nas relações de trabalho, nas relações familiares e nas relações afetivas. Este artigo se propõe a discutir dominação masculina e dominação patriarcal presente nas canções populares discutidas e reescritas na página Arrumando Letras presente na mídia social Facebook, bem como a compreensão dos fenômenos, valores e costumes estudados pela ética, compreendida como a Ciência da moral.

Os objetivos específicos incluem: a) verificar as contribuições bibliográficas no que tange ao arcabouço teórico e conceitual sobre ética; b) discutir por intermédio das postagens

\begin{tabular}{l} 
(C) RDBCI: Rev. Digit. Bibliotecon. Cienc. Inf. \\
\hline
\end{tabular}


da página Arrumando Letras, a dominação patriarcal e masculina contra as mulheres presente nas músicas populares entre brasileiros e brasileiras; c) analisar a página Arrumando Letras como um importante espaço de militância e promoção de debate sobre respeito entre gêneros e herança de uma cultura patriarcal; d) Refletir como a competência crítica em informação é aplicada na página e como contribui com a formação dos seguidores da mesma. Esta discussão se justifica por refletir e desconstruir valores que, por muito tempo, foram naturalizados influenciando o comportamento submisso de muitas mulheres em relação aos homens de seu convívio.

A importância da informação nos meios digitais, em especial nas mídias sociais (facebook, intagram, twitter) que possuem redes sociais online, tem se destacado na Ciência da Informação e na sociedade da informação para estudos de diferentes situações e questões sociais, como ressaltam Gasque (2010), Vitorino e Piantola (2009). A competência crítica em informação passa a "funcionar como uma ferramenta essencial na construção e manutenção de uma sociedade livre, verdadeiramente democrática, em que os indivíduos fariam escolhas mais conscientes e seriam capazes de efetivamente determinar o curso de suas vidas" (VITORINO; PIANTOLA, 2009, p. 136).

Um indivíduo presente em uma rede social está sujeito a uma estrutura de distribuição de poder e de dependência presentes na sociedade e que são transportadas para as redes sociais quando online. Os movimentos que são criados nestas redes, organizam e configuram um novo campo de ações e representações visando a intervenção social com foco no conhecimento prático para transformar a realidade vivida (MARTELETO, 2001). Neste caso, a presença digital no Facebook da Página Arrumando Letras busca desconstruir o patriarcado por intermédio da denúncia e reescrita de letras de músicas que perpetuam conceitos machistas em nossa sociedade.

\section{2 ÉTICA, MORAL E VIOLÊNCIA}

Compreende-se a Ética, a partir dos escritos de Aristóteles (1991), Sánchez Vázquez (2004), Capurro (2001) e González de Gómez (2009), como parte da filosofia que estuda os princípios que motivam, disciplinam e/ou orientam o comportamento humano no que tange à construção de valores morais em diferentes realidades sociais. Desta forma, a Ética enquanto área de estudo, tornaria-se indispensável para a vida humana, uma vez que a organização social é baseada em valores morais dentro do direito, da política, das profissões, da ciência, das religiões.

Para que se reflita sobre ética, é necessário entendermos seu conceito. Conforme Pizarro (2010, p. 22), "a ética é um ramo da filosofia. Considerada ciência, avalia a conduta humana perante o ser e os seus semelhantes, uma vez que confronta o desempenho humano em relação às normas comportamentais estabelecidas num dado contexto social”.

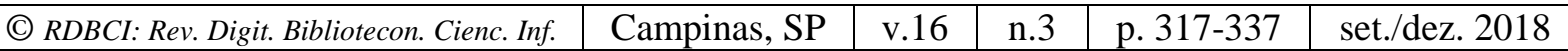


Embora a ética ainda seja confundida com a moral, existem aspectos que as distinguem. Uma das primeiras distinções a serem realizadas, seria o discernimento de cada termo, onde a ética em sua etimologia possui relação com Ethos, que em grego significa "civilização", "núcleo cultural de um povo, ou também a busca de humanização a partir de um ideal de sociedade justa" (ZITKOSKI; TROMBETTA, 2011, p. 104). O termo moral, deriva de Morus, palavra latina que significa "costumes" e "que nos remete para um conjunto de valores e costumes relativo a cada povo situado historicamente" (ZITKOSKI; TROMBETTA, 2011, p. 104). Para Tugendhat (1996) citado por Pizarro (2010, p. 24), uma das formas de definir a moral seria empregando as palavras "bom" e/ou "mau". Visto que quando nos referimos que algo é bom ou mau em vista de um determinado objetivo empregamos termos de forma absoluta, como por exemplo, ao dizermos que

\footnotetext{
humilhar alguém é mau. Não se entende que é mau para a vítima da humilhação, ou mesmo para a sociedade, e sim a humilhação simplesmente é ruim, o que ainda deve ser esclarecido, ou seja, uma vez que o ato de humilhar é visto como um comportamento social, o mesmo deve ser regulado. E é neste sentido, objetivamente, que se definem o discurso dos juízos morais (PIZARRO, 2010, p. 24).
}

No que se refere aos aspectos históricos, o estudo da ética pode ser dividido em quatro doutrinas, conforme Sánchez Vázquez (1975), que são a Ética grega, a Ética Cristã Medieval, a Ética Moderna e a Ética Contemporânea. Na contemporaneidade, existem algumas correntes éticas que são posteriores à doutrina do iluminismo. Estas correntes são:

a) Ética utilitária: também conhecida como utilitarismo, é uma doutrina que possui Jeremy Bentham como precursor, sendo constituída no fim do século XVIII, início do século XIX, e "consiste em afirmar que os indivíduos buscam alcançar a felicidade através da razão e da lei” (PIZARRO, 2010, p. 28).

b) Ética da Alteridade: construída no século XX, “[...] propõe na base a ideia de luta pela sobrevivência na satisfação das necessidades básicas, impondo-se ao peso de existir; de luta para obter um lugar ao sol na esfera da economia e da sociedade" (PIVATTO, 2000, p. 80).

c) Ética da Finitude: Criada no século XX por Heidegger, a ética da finitude se baseia no princípio da razão suficiente, ancorada na finitude do ser e do pensar. Esta corrente ética irá possibilitar a destruição dos sistemas morais, como por exemplo, da utilidade (LOPARIC, 2000 apud PIZARRO, 2010, p. 33).

d) Ética do Discurso: Criada por Karl-Otto Apel no século XX, a ética do Discurso tem como base "a noção da cultura ocidental ser uma cultura da razão, sendo a razão o foco ordenador de todos os discursos” (HERRERO, 2000 citado por PIZARRO, 2010, p. 35).

e) Ética da Responsabilidade: Esta "se fundamenta na idéia de dever e responsabilidade do homem [e da mulher] perante a natureza e as futuras

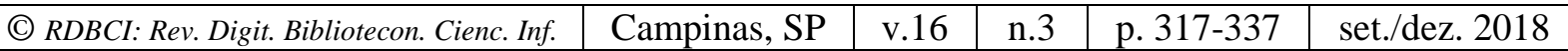


gerações. Atualmente a técnica moderna condiciona o agir humano" (PIZARRO, 2010, p. 39).

f) Ética Profissional e Deontologia: É definida por Mattos (1977, p. 1) como "a ciência normativa que estuda os deveres e direitos dos profissionais".

Embora faça parte de diversos núcleos que elaboram e movimentam as estruturas sociais, nem todas as pessoas têm condições de refletir e questionar a Ética em seus contextos, pois vivemos uma realidade na qual a educação básica pública é precária (principal instituição que promove a troca de aprendizado na formação da pessoa), e desta forma, diminui as possibilidades de aprofundamento filosófico sobre Ética, sobretudo, com a reformulação do ensino médio no Brasil (BRASIL, 2016).

Na perspectiva do Ensino superior, é possível oportunizar uma reflexão um pouco maior sobre Ética. Sánchez Vázquez (2004) ressalta a importância dos estudos da ética para as formações acadêmicas e a relevância do debate sobre temas como: a essência da moral, responsabilidade moral, doutrinas éticas fundamentais para a vivência em sociedade, entre outros. Ao assumirmos a definição da ética como campo da filosofia que estuda a moral, indagamos: O que seria a moral e a responsabilidade que a pessoa tem diante de suas ações? É algo construído a partir de uma visão romanceada? Não se analisarmos sob a perspectiva da Ética deontológica defendida por Kant (2002), nesta visão ela não é atrativa, mas dotada de rigor, formalidade e racionalidade. Critica a ideia de felicidade e a utilidade como critérios para estabelecer o que é o bem. Tal visão é relevante para esta discussão se pensarmos alguns valores morais como algo que impede a barbárie, uma vez que pode conter a violência, pois, a partir de códigos legais, sujeita pessoas a penalidades.

Entende-se a violência como tudo que age contra a natureza de sujeitos, toda força contra a espontaneidade e liberdade de alguém através da coação, constrangimento, agressão física, tortura e atos de brutalidade. Consistem na transgressão contra o que a sociedade acha justo, o que se apropria como direito, isso inclui o abuso moral ou sexual, a opressão, e/ou intimidação pelo medo ou terror (CHAUÍ, 1998). A partir disso, reflete-se sobre as concepções de violência e opressão serem relativas e passíveis de diversas interpretações, sobretudo, no que se refere à diferença de tratamento entre os gêneros, sobrepondo, inclusive legalmente o favorecimento à dominação masculina.

Ribeiro (2013), critica os ideais defendidos pela dominação masculina como parte de um pressuposto que inferioriza a mulher em relação ao homem por uma perspectiva biológica, nessa abordagem, por ter útero e ovário a mulher seria inferior. A partir dessa crença, muitos grupos sociais fizeram-nos acreditar que em sentido moral, político e intelectual também seríamos inferiores. Culturalmente, existiu e existe toda uma estrutura hierarquizada que contribui para a desvalorização moral da mulher de uma maneira violenta (mesmo que não física) a partir de valores da estrutura dominante na sociedade que vivemos.

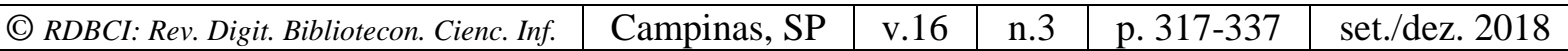


Com base no exposto, nota-se que a ética, o bem e os valores morais que regem uma comunidade nem sempre conte mplam e promovem a equidade entre os gêneros, as etnias, os povos, as classes sociais. As manifestações culturais através da música, das artes e da literatura, estudadas e apropriadas ao longo da vida pela educação familiar, educação escolar, interação social em diversos grupos em algum momento, contribuiu e/ou contribui para que essa estrutura dominante continue determinando padrões de comportamento.

\section{COMPETÊNCIA CRÍTICA EM INFORMAÇÃO}

O Conselho de Administração da ACRL (Association of College \& Research Libraries) rescindiu os Padrões de Competência em Informação para Ensino Superior, originalmente aprovados em 2000, em 25 de junho de 2016, na Conferência Anual ALA de 2016 em Orlando, Flórida. A atual definição de Competência em Informação (Information Literacy) da ACRL é:

A competência em informação é um conjunto de habilidades que requerem dos
indivíduos que "reconheçam quando as informações são necessárias e tenham a
capacidade de localizar, avaliar e usar efetivamente as informações necessárias".
Competência em informação, é também, cada vez mais importante no ambiente
contemporâneo de rápidas mudanças tecnológicas e de proliferação dos recursos de
informação (AMERICAN LIBRARY ASSOCIATION, 2000, p. 2, tradução nossa).

A dimensão crítica da competência em informação é o amálgama que diferencia o que é simplesmente disponibilizado, técnico ou ensinado (formal ou informalmente pelos dispositivos técnicos ou aparatos de poder), daquilo que é criticamente apreendido e utilizado pela pessoa competente crítica em informação. A competência crítica em informação funcionaria como uma ferramenta de empoderamento e libertação das pessoas. Sob esta perspectiva, a competência crítica em informação é essencial ao cidadão contemporâneo para lidar com o volume de informações que recebe diariamente, e, para além disso, avaliar criticamente a informação que o cerca.

Segundo Freire (1967), a esfera humana guarda conotações de pluralidade, transcendência, criticidade, consequência e temporalidade. É plural na medida que se relaciona com o outro e com o mundo de maneira diversa e adaptável. É naturalmente crítica, pela "captação que faz dos dados objetivos de sua realidade, como dos laços que prendem um dado a outro, ou um fato a outro", e por isso, "reflexiva e não reflexa, como seria na esfera dos contatos" (FREIRE, 1967, p. 40). Desta forma, a interação que acontece nas postagens da página Arrumando letras, contempla a dimensão dialógica e crítica que colabora com a construção da competência crítica em informação e com a apropriação da dimensão do "eu" no mundo.

\section{4 a desconstrução da dominaÇão patriarcal na CUltura muSiCAL}

\begin{tabular}{|c|c|c|c|c|c|}
\hline (C) RDBCI: Rev. Digit. Bibliotecon. Cienc. Inf. & Campinas, SP & v.16 & n. 3 & p. 317-337 & set./dez. 2018 \\
\hline
\end{tabular}


Entendemos por patriarcado, "o poder que o homem exerce por meio dos papéis sexuais" (SOUZA, 2013, p. 476). Ao associar patriarcado e a perspectiva de dominação entre gêneros num contexto capitalista, podemos observar que a estrutura de dominação que sofremos atualmente tem um viés sócio-histórico: de um lado, trata a dominação patriarcal como emergida durante a industrialização capitalista e, de outro, que trata essa dominação fundamentada no ponto de vista religioso.

De acordo com a visão de dominação patriarcal socioeconômica advinda da industrialização (contexto europeu), a mulher foi excluída da economia dominante (masculinização do trabalho) e subsumida pelas atividades que o homem exercia, tornando-as assim, economicamente dependente de seus cônjuges. Entretanto, a necessidade do lucro e estímulo ao consumo pregados pela ideologia capitalista mudou a lógica do capital (mais valia), onde a imposição de gerar riqueza passa ser o objetivo de todas as pessoas que vivem nesse sistema. Neste contexto, mulheres e crianças passaram a ocupar os espaços de trabalho, mas, submetidas a salários menores mesmo que nas mesmas condições e exercendo as mesmas funções que homens.

Na medida em que o avanço tecnológico crescia (sob o enquadramento no tempo e espaço a Europa do século XIX), era cada vez mais necessária a educação da população. As mulheres, então, começaram a ocupar novas funções de trabalho, que englobaram, sumariamente, atividades de educação, sem grande valorização moral, uma vez que elas eram vistas como especialistas em cuidar das crianças (SOUZA, 2013).

No final do século XIX e início do século XX, ocorreram mudanças na luta feminina por seus direitos, mulheres enquanto ocupantes do mercado de trabalho exigiram o direito ao exercício da cidadania, sobretudo o direito ao voto estimulado pelo movimento sufragista que se iniciou em Londres, foi difundido por diversos países da Europa, e, chegou no Brasil durante a segunda década do século XX (KARAWEJCZYK, 2013). Apesar das manifestações, a representatividade na ocupação desses espaços não foi bem recebida, pois exigir igualdade de direitos diante uma estrutura moral patriarcal, silenciou muitas mulheres e inibiu outras de aderirem ao movimento, uma vez que as militantes, por diversas vezes, foram ridicularizadas pela mídia, pois eram consideradas "machonas", mal-humoradas, sem vaidade e indesejada pelos homens (PIZA, 1994).

Costa (2013) ressalta que as discussões feministas no Brasil, a fim de combater a estrutura moral dominante do patriarcado, cresceu sobretudo na ocupação e exaltação da mulher nas artes plásticas, música, literatura e política. Enfatizamos que tais mudanças não ocorreram em todo o território nacional e nem atendeu à todas as classes sociais. Além disso, essas mudanças não têm o mesmo significado para todos os gêneros e diversidades étnicas. A ampliação dessas lutas para os diferentes grupos sociais ocorreu sobretudo nos últimos trinta anos, e sua popularização se deu através do desenvolvimento das Tecnologias de Informação, em especial, o acesso à internet. 
A outra perspectiva que enquadra a dominação do patriarcado, delimitada anteriormente, é facilmente vista sob uma perspectiva religiosa cristã. No contexto bíblico, Deus é representado no masculino e a mulher é, em diversos livros, não só inferiorizada em relação aos homens como também responsabilizada pela noção de pecado original. As igrejas por sua vez, reforçam essa lógica de dominação, afirmam-se a favor dos princípios que respeitam a vida, entretanto não promovem a equidade nos discursos uma vez que gêneros diferentes do masculino heterossexual sempre são subjugados pela reprodução da dominação patriarcal em relação a outros gêneros (ROSADO-NUNES, 2006).

Diante da trajetória sobre origem, afirmação e perpetuação da estrutura dominante patriarcal para as estruturas sociais, podemos compreender como essa estrutura impactou nas formas de viver das mulheres: cisgêneras, transgêneras, lésbicas e demais gêneros; destacando as diferenças de vivências também numa perspectiva étnica que respeite os locais de fala de cada grupo, não esquecendo nem silenciando estes grupos nas discussões.

A dominação patriarcal influenciou e, ainda hoje, tem grande responsabilidade no assédio contra as mulheres, uma vez que na cultura, no consumo, na representação política, na escolha da carreira, nas relações afetivas, em algumas religiões, no exercício da cidadania e no direito (sobretudo na proteção legal), vivemos uma realidade que, apesar das mudanças e do crescimento das militâncias, ainda fere, mata e submete muitas mulheres a violências ao longo da vida.

\section{REESCREVENDO AS LETRAS}

A fim de atender aos objetivos desta investigação, mostraremos a dominação patriarcal em músicas populares brasileiras, que, moldam o imaginário sobre as formas que as pessoas se relacionam e, muitas vezes, negam a equidade de direitos nas relações sociais. Muitas são canções onde estão explícitas as violências, o silenciamento, a pedofilia, as relações abusivas e, até mesmo, o estupro sofrido pelas pessoas que não correspondem à visão cis gênera masculina. Tais atrocidades, que por vezes romanceadas, ou até mesmo compreendidas moralmente como certas e/ou naturais, são criticadas e vêm causando debates, compartilhamentos e sofrendo avaliações (através das reações likes, love, haha, sad e grrr) a partir das postagens da página Arrumando Letras no Facebook.

As redes sociais online ou mídias sociais consistem em oportunidades de interação através de diálogos e/ou outras formas de comunicação em diversos ambientes e grupos sociais. Marteleto (2010) salienta que, as redes sociais online permitiram uma nova forma de compreender a sociedade, pois ultrapassam os princípios tradicionais que discorriam sobre essas interações unicamente contemplarem papéis previamente instituídos às pessoas em suas respectivas funções. 
A interação nas diversas redes sociais online também pode ocorrer através das mídias sociais, estas, "podem ser conceituadas como espaços de colaboração, de compartilhamento de informações, de construção coletiva de conhecimento, por meio de interações pela internet" (DOTTA, 2011, p. 610). Na atualidade, um dos espaços mais populares de interação é a mídia social Facebook. Neste espaço, é possível interagir com diversos grupos através de uma rede de amigos ou por meio de páginas e grupos de discussão sobre determinados interesses.

A popularidade da mídia social Facebook, a transformou em um dos maiores espaços de produção e compartilhamento de informações. Compreende-se compartilhamento de informações como a ação de disseminar determinados conteúdos a partir de interesses individuais sob diferentes contextos sociais (CORRÊA; ROZADOS, 2016). Nesta perspectiva, os conteúdos compartilhados pelas pessoas em sua timeline, dentre eles pensamentos individuais, notícias, vídeos, artigos, entre outras manifestações, refletem posicionamentos políticos, culturais e éticos que determinada pessoa ou grupo possui.

A escolha da página Arrumando Letras se deu a partir da visualização de uma postagem que refletia sobre a naturalização do assédio pela imposição da vontade de um homem sobre a escolha de uma mulher querer ou não se relacionar romanticamente com ele, presente na canção "Vidinha de balada", de uma famosa dupla de sertanejo universitário. A partir de então, notou-se o quanto a dominação patriarcal, por diversas vezes está presente nas relações amorosas e no imaginário das pessoas sobre os relacionamentos, frequentemente romantizadas em muitas canções brasileiras, englobando diversos gêneros musicais. As canções analisadas pela página são populares entre diferentes classes sociais, o que desmistifica, a pré-suposição de que esta violência simbólica (BOURDIEU, 2001) ocorre apenas entre as classes mais carentes.

A página foi criada por uma advogada paranaense, com o objetivo de mostrar o quanto o machismo estrutural está presente em várias canções populares. Apenas quatro dias após a criação da página (24 de março de 2017) o compartilhamento dos conteúdos viralizou, reunindo mais de 100 mil seguidores. Atualmente, quase sete meses após sua criação, a página é seguida por mais de 250 mil pessoas (VINHAL, 2017).

De forma dinâmica, as postagens acontecem por meio de fotos que expõe as letras de músicas e são rabiscados os trechos que indicam atitudes abusivas de homens em relação às mulheres e sinalizam e estimulam uma atitude respeitosa nas investidas sexuais e nos relacionamentos. Como, por exemplo a canção Maria Chiquinha popularizada na voz de uma famosa dupla sertaneja infantil. 


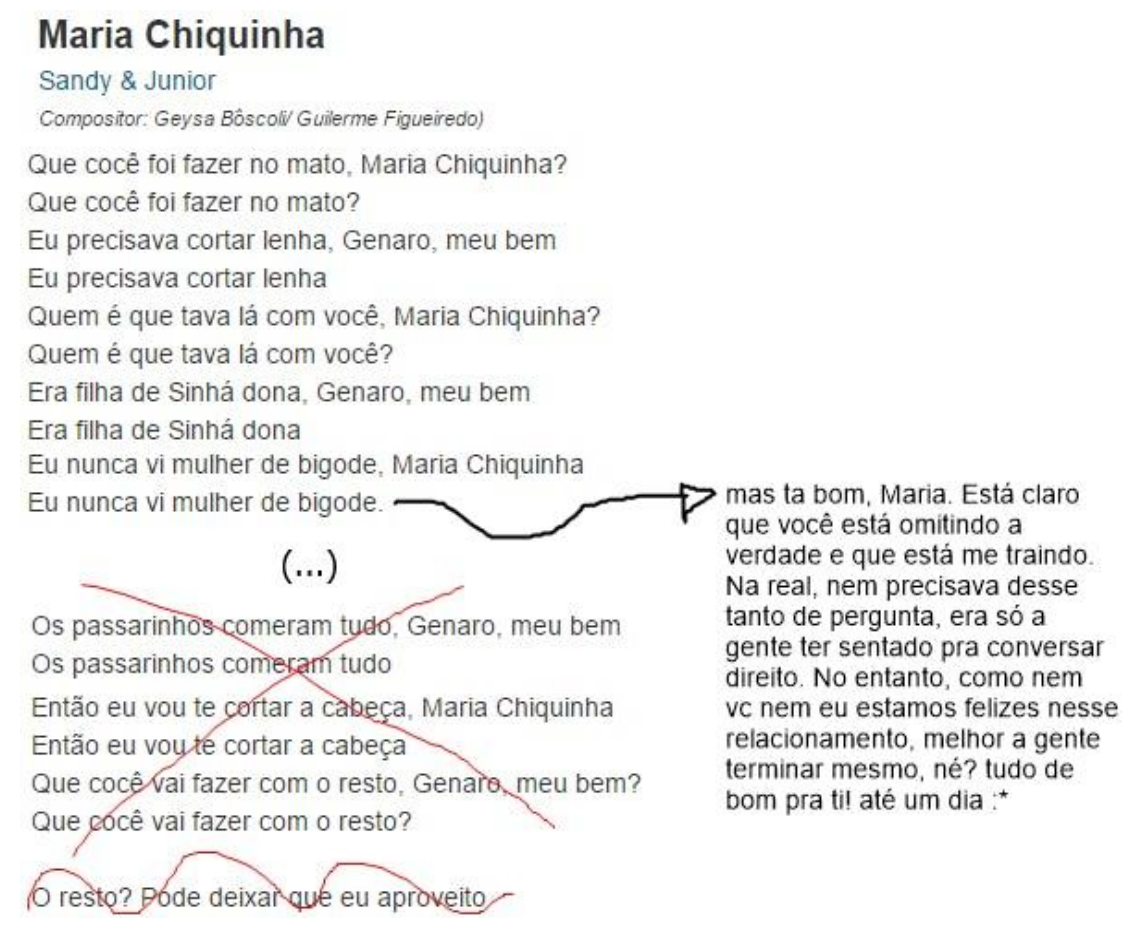

Figura 1. Letra da canção Maria Chiquinha Fonte: Página Arrumando Letras (2017).

Disponível em: <https://www.facebook.com/paginaarrumandoletras/>. Acesso em: 18 Out. 2017.

A maioria das postagens referem-se ao gênero musical sertanejo. Entretanto, também encontramos na página letras do funk, pagode, samba, axé, rock internacional, rock nacional, entre outros gêneros musicais. Todas as postagens são acompanhadas por textos que visam o combate à dominação patriarcal e abrem uma grande oportunidade para discussão e desconstrução desses valores, contribuindo também para a implementação da competência crítica em informação. As postagens estimulam a sororidade entre as mulheres e evocam em seus textos o apoio e o desenvolvimento da empatia entre pessoas. O slogan "aqui o preconceito não tem licença poética" é um forte chamariz na luta pela equidade entre gêneros.

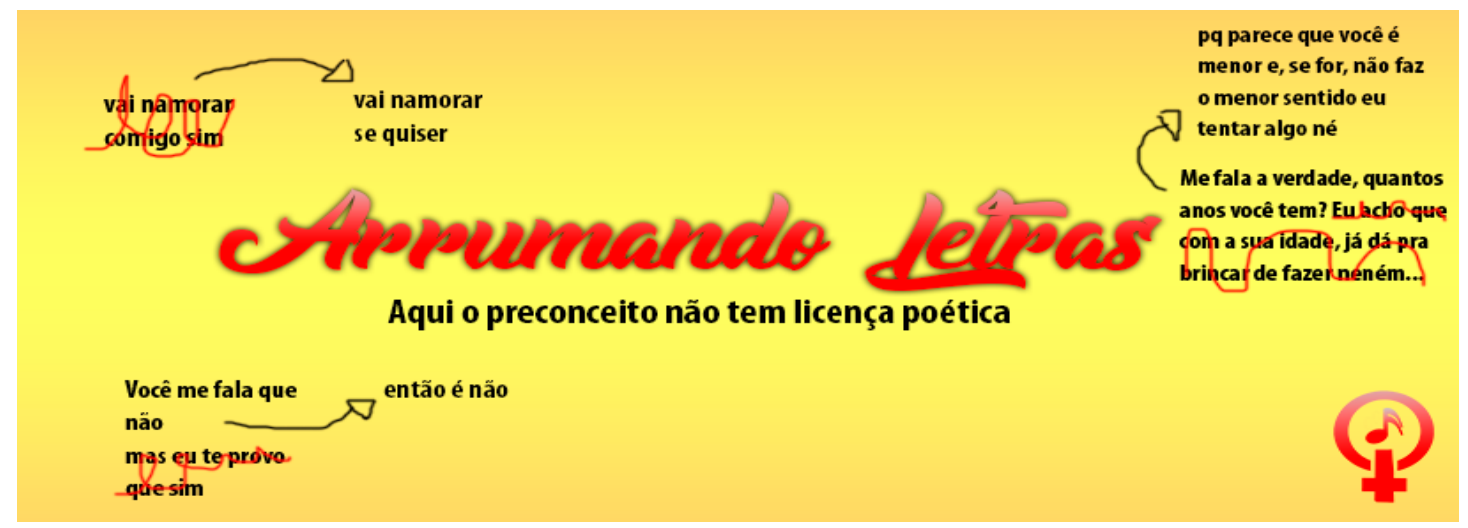

Figura 2. Foto de capa da página Arrumando letras no Facebook Fonte: Página Arrumando Letras (2017). 
Disponível em: 〈https://www.facebook.com/paginaarrumandoletras/>. Acesso em: 18 Out. 2017.

Nos últimos meses, as postagens também passaram a contemplar letras de empoderamento feminino, que mostram que, em contrapartida à estrutura patriarcal existe um movimento de luta e desconstrução na cultura musical, como por exemplo a letra Maria de Vila Matilde, popular na voz de Elza Soares. Essas publicações são postadas a cada sábado sobre o título de "Letras para amar".

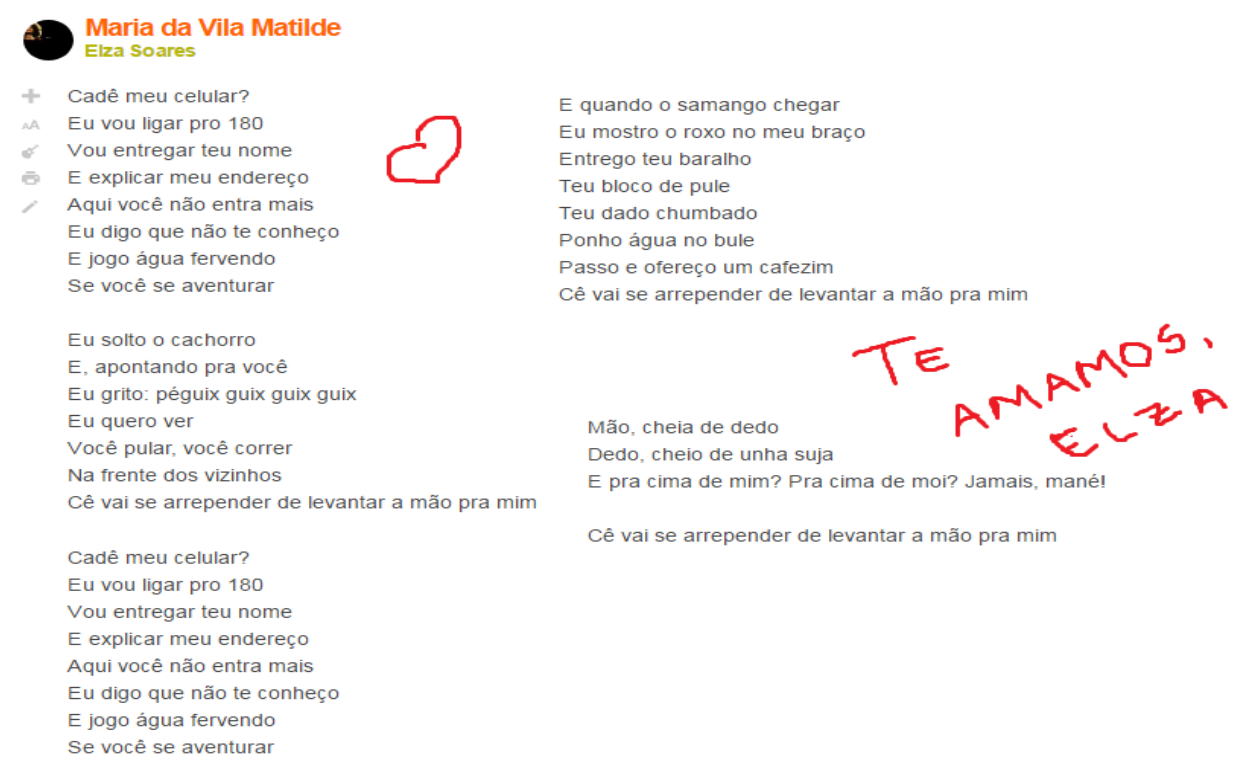

Figura 3. Letras para amar - Maria de Vila Matilde Fonte: Página Arrumando Letras (2017).

Disponível em: 〈https://www.facebook.com/paginaarrumandoletras/>. Acesso em: 18 Out. 2017.

A popularização desta, assim como de outras páginas na mídia social Facebook, que tem por objetivo a reflexão e combate à dominação patriarcal, são importantes por impulsionar e promover a militância e o empoderamento de mulheres, bem como a reflexão sobre aspectos culturais que as oprimem. $\mathrm{O}$ alcance da militância ainda está longe de atender as demandas nacionais, uma vez que o acesso à mídia social Facebook, local onde este debate é mais popular, bem como a reflexão sobre a equidade de direitos em diversos espaços físicos e virtuais, ainda não atinge todas as realidades sociais.

A partir disso, reforça-se a necessidade de compreensão de pesquisadores e profissionais da informação sobre a ética intercultural, que consiste na compreensão de que os valores morais modificam nos diferentes contextos sociais (CAPURRO, 2001). A abordagem deve ser cuidadosa, pois imposição de uma cultura empoderadora pode ser 
invasiva e agressiva, incomparável à dominação patriarcal, uma vez que as relações de poder são diferentes, mas, igualmente impositivas quando a proposta não tem o objetivo de instruir e promover uma reflexão autônoma. Para atender a esta reflexão, adotamos o conceito de competência crítica em informação como uma possível saída, uma vez que prioriza o entendimento centrado na pessoa e na interação entre sujeitos e não somente em uma perspectiva mecânica sobre busca, acesso e uso de informações (BEZERRA, 2015).

\section{METODOLOGIA}

A metodologia utilizada é de natureza exploratória e abordagem qualitativa. Utilizamos a Análise de Redes Sociais (ARS) de Regina Maria Marteleto e Maria Inês Tomaél (2005), oriunda da Antropologia cultural e da Sociologia, visto que "investiga as aspirações, crenças, valores e os reflexos que os padrões de relacionamento produzem no contexto em que se desenvolvem" (MARTELETO; TOMAÉL, 2005, p. 84). Alguns artigos utilizaram a ARS para análise de conteúdos dispostos em mídias sociais, entre eles, destacamos, "O Uso da Rede Social Como Prática de Informação: um estudo no grupo 'Mulher, me Ajuda Aqui' do Facebook", de Oliveira et al (2017); o artigo "Redes sociais online como espaços de memória: uma visão a partir da página "Recife de antigamente" de Santos e Albuquerque (2017) e "Suporte social informacional mediado por grupos no facebook: um estudo de caso" de Caran e Biolchini (2015).

O universo desta pesquisa é a página Arrumando Letras alocada na mídia social Facebook. Adotou-se como instrumento de coleta de dados, uma planilha eletrônica com dados sobre as datas das postagens, os assuntos abordados e número de interações (compartilhamentos, comentários, curtidas). Foram mapeadas postagens da página no período de 01 de julho a 12 de outubro de 2017. Posteriormente, selecionou-se para a discussão, três postagens que apresentassem o maior número de interação (curtidas, comentários e compartilhamento) das pessoas que curtiram e seguem a página. Diante disso, adotamos enquanto técnica, a análise de conteúdos que, de acordo com Laurence Bardin (2004, p. 38), "aparece como um conjunto de técnicas de análise das comunicações, que utiliza procedimentos sistemáticos e objetivos de descrição do conteúdo das mensagens" e possui como intenção, a "inferência de conhecimentos relativos às condições de produção (ou, eventualmente, de recepção), inferência esta que recorre a indicadores (quantitativos ou não) (BARDIN, 2004, p. 38).

Na Ciência da informação, essa técnica foi utilizada em diversas pesquisas, como, por exemplo, no artigo "Bibliotecas universitárias das instituições estaduais de ensino superior paranaenses e a mediação da informação no Facebook" de Santos Neto e Almeida Júnior (2017); “A competência em informação e o comportamento informacional dos usuários de bibliotecas híbridas: um estudo comparativo no Brasil e na Escócia" de Rafaela Silva e colaboradores (2018); e, "O Uso da Rede Social Como Prática de Informação: um estudo no grupo 'Mulher, me Ajuda Aqui' do Facebook” de Rebecca Oliveira e outros (2017).

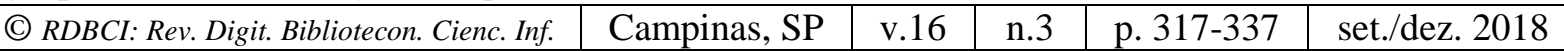


Para análise das postagens deste estudo, realizamos a análise de conteúdo, visto que foram lidos cada um dos comentários realizados nas postagens de maior interação, verificado o gênero binário (masculino ou feminino) da pessoa que comentou, analisados os seus discursos (na perspectiva de quem fala) a partir das perspectivas da Competência crítica em informação e interação do público-alvo nas postagens.

\section{APRESENTAÇÃO E DISCUSSÃo dOS RESULTADOS}

A seguir, apresentaremos e discutiremos os resultados obtidos na página Arrumando Letras a partir das perspectivas da Competência crítica em informação e interação do públicoalvo nas postagens.

\subsection{Publicações da página e a interação do público}

Analisamos as postagens da Página Arrumando Letras no período de 01 de julho de 2017 a 12 de outubro de 2017. Ao total, foram publicadas 19 postagens, sendo que dos tipos de publicações encontradas, 11 se relacionam a letras reescritas de músicas consideradas machistas, com apologia ao estupro, assédio sexual, com termos pejorativos às mulheres, sobre relacionamentos abusivos, entre outros, além de cinco postagens da categoria "letras para amar" e três postagens com divulgações de sorteios e promoções da página (Gráfico 1).

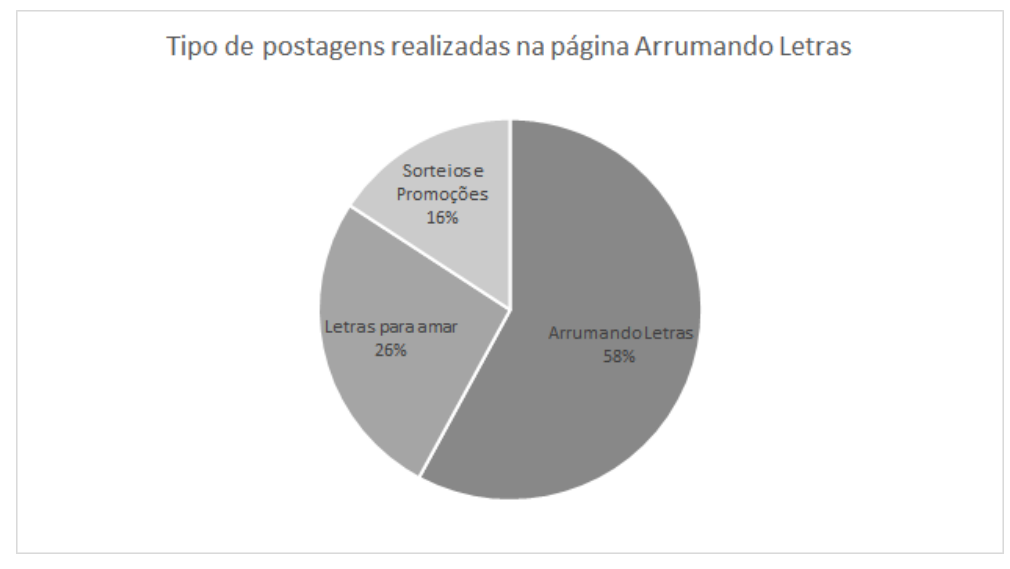

Gráfico 1. Tipo de postagens realizadas pela Página Arrumando Letras no período de 01 de julho a 12 de outubro de 2017.

Fonte: Dados da Pesquisa (2017).

Quando analisamos as interações (comentários, reações e compartilhamentos) nas publicações realizadas, observamos que a "Arrumando Letras" chama atenção do público quanto ao machismo, cultura do estupro e ao assédio, bem como da imposição à mulher ter que estar em um relacionamento que ela não deseja, os relacionamentos abusivos com ciúmes em excesso e violência, além da atribuição de termos pejorativos à ela. As interações são

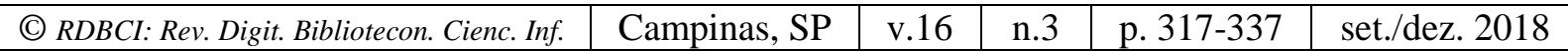


reflexo de que o público, que antes pensava na música apenas como forma de arte, atualmente pode também refletir a mensagem que está sendo passada por intermédio dessas músicas (Figura 4-B).

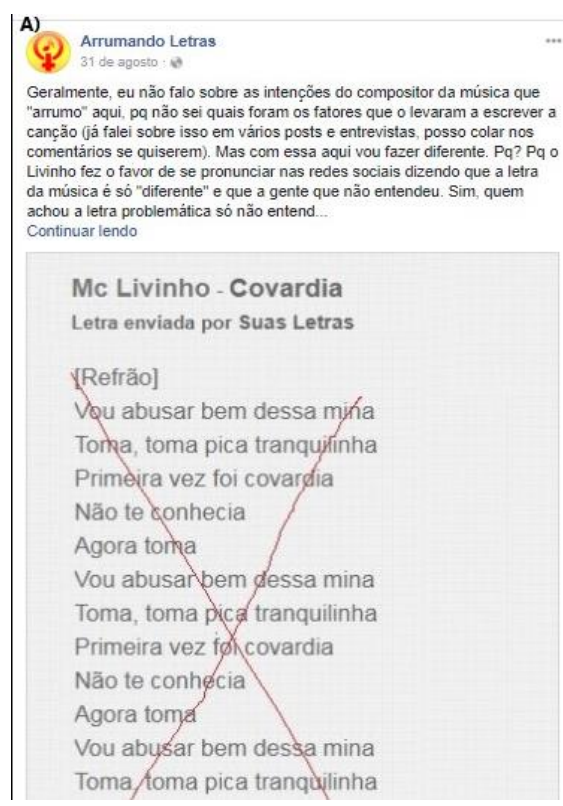

\begin{tabular}{|c|c|c|c|}
\hline \multirow{2}{*}{ B) Data } & \multicolumn{3}{|c|}{ Arrumando Letras } \\
\hline & Comentários & Reações & Compartilhamentos \\
\hline $01 / 07 / 2017$ & 0 & 0 & 0 \\
\hline $06 / 07 / 2017$ & 57 & 812 & 60 \\
\hline $11 / 07 / 2017$ & 14 & 255 & 29 \\
\hline $15 / 07 / 2017$ & 0 & 0 & 0 \\
\hline $19 / 07 / 2017$ & 29 & 445 & 48 \\
\hline $28 / 07 / 2017$ & 42 & 620 & 63 \\
\hline 03/08/2017 & 295 & 3400 & 577 \\
\hline $05 / 08 / 2017$ & 0 & 0 & 0 \\
\hline $14 / 08 / 2017$ & 45 & 741 & 38 \\
\hline $19 / 08 / 2017$ & 0 & 0 & 0 \\
\hline $24 / 08 / 2017$ & 22 & 432 & 44 \\
\hline $31 / 08 / 2017$ & 1600 & 10000 & 5513 \\
\hline $02 / 09 / 2017$ & 0 & 0 & 0 \\
\hline $07 / 09 / 2017$ & 22 & 348 & 13 \\
\hline $13 / 09 / 2017$ & 65 & 700 & 42 \\
\hline $22 / 09 / 2017$ & 0 & 0 & 0 \\
\hline $07 / 10 / 2017$ & 0 & 0 & 0 \\
\hline $08 / 10 / 2017$ & 12 & 280 & 3 \\
\hline $12 / 10 / 2017$ & 0 & 0 & 0 \\
\hline Total Geral & 2203 & 18033 & 6430 \\
\hline
\end{tabular}

Figura 4. A) Postagem que reescreve a Música Covardia, de um MC, com maior número de interações no período de estudo; B) Interação do público com comentários, reações e compartilhamento nas postagens que arrumam as letras com as postagens realizadas na página “Arrumando Letras" no período de 01 de julho a 12 de outubro de 2017, tendo o dia 31 de agosto com maior interação.

Fonte: Dados da Pesquisa (2017)

Conforme Figura 4-A, a publicação realizada no dia 31 de agosto de 2017, foi a que mais causou interação com o público-alvo da página. Esta postagem se referia à música Covardia, de um Mc e, que segundo, a Arrumando Letras (2017, s.p.):

[...] a letra de "Covardia" [é] uma apologia à violência contra a mulher e, olha só, o Dicionário Aurélio, que define a palavra "abuso" como: 1 - Usar ou consumir de forma excessiva, errada ou inconveniente. 2 - PROCURAR RELAÇÕES SEXUAIS COM ALGUÉM SEM O SEU CONSENTIMENTO. 3 - Insultar. 4 - Agir de forma a servir apenas os próprios interesses, mesmo se prejudicando alguém. Mas, claro, como vc [MC] também disse no seu vídeo, nós todos fazemos parte da "galera do mimimi". No mais, achei interessante que vc tb diz que, por causa da ejaculação precoce, O CARA não conseguiu curtir muito a transa da primeira vez e, por isso, voltou pra abusar a mina. Ao que parece, tudo gira em torno do prazer desse homem, não é mesmo? A mulher não tem muita vez - nem voz - aqui nessa relação.

A partir desta reflexão, é importante frisar que o Brasil é o quinto no mundo no que se refere à taxa de feminicídio e estudos mostram que $70 \%$ das mulheres já foram vítimas de violência física e/ou sexual por parte de um parceiro íntimo. Conforme a Organização Mundial da Saúde (OMS), o número de assassinatos é de 4,8 para cada 100 mil mulheres. O Mapa da Violência de 2015 apresenta que, de 1980 a 2013, 106.093 mulheres morreram por

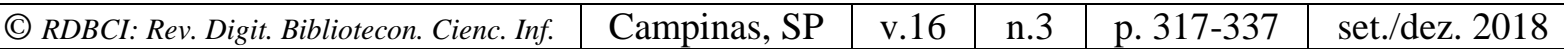


sua condição de ser mulher. Além disso, a OMS afirma que, em todo o mundo, $35 \%$ das mulheres já sofreram violência física ou violência sexual praticada por parceiro ou por um não-parceiro em algum período da vida (DOSSIÊ..., 2017; OMS, 2012; WAISELFISZ, 2015).

O que chamamos atenção aqui é que, embora as letras de músicas não sejam totalmente responsáveis por tais fatos, elas colaboram para a manutenção da violência e assédio contra a mulher. Como já dissemos, estamos em um país constituído por um patriarcado que reforça e, ainda permite aspectos que condicionem a mulher em posição de submissão ao homem, sem qualquer poder decisório em relação ao seu corpo e ao direito de dizer não.

\subsection{A competência crítica em informação e a interação nas postagens}

Como exposto anteriormente, Paulo Freire (1967) considera o aprendizado dialógico alinhado com a natureza social do humano ao se relacionar com o outro e com o mundo. Sendo assim, essa natureza se replica nas mídias sociais como o Facebook. Isso é sugerido na pluralidade dos tipos de comentários e comentadores nas postagens da página Arrumando Letras.

Através da análise dos comentários é possível aferir que este diálogo favorece a competência crítica em informação, percebendo que: a) estimulam a busca por mais informação; b) propicia o diálogo entre pessoas com visões, ideologias, experiências e opiniões distintas; c) desperta a percepção crítica a respeito das músicas, do patriarcado, do machismo e da posição da mulher na sociedade; d) desperta a curiosidade por mais informação; entre outras oportunidades.

Pensando nas características que aferem a competência crítica, destacamos como exemplos: busca por mais informação (o usuário vai em busca de alguma informação específica e retorna ao grupo com esta resposta), percepção crítica sobre as músicas e páginas (o usuário exprime surpresa ou gratidão pela nova percepção), despertar da curiosidade (o usuário pede explicação ou correção ante uma dúvida). Apresentamos abaixo, alguns exemplos destas interações sob a perspectiva da competência crítica em informação:

\footnotetext{
"Não sei se é realmente necessário mas não custa ressaltar: eu tô aqui pra formar opinião; então, por favor, se você não concorda comigo, me explica porque eu tô errado ao invés de comer meu fígado kkkk" (HOMEM)

"Pelo menos era como eu tinha interpretado. Me corrijam se eu estiver errada (educação pfvr)" (MULHER).

"Estou aprendendo que existe este tipo de coisas ainda" (MULHER)

"Letra dos Beatles com "abuso" sexual?? Essa novidade pra mim! Por favor, citem os exemplos dado... Odeio boatos" (MULHER)
} 
Resposta à postagem acima: "Pra quem pediu, numa simples pesquisa no Google já encontrei no primeiro resultado: http://blogueirasfeministas.com/2011/11/musicasbeatles/"' (HOMEM)

\begin{abstract}
"Que explicação maravilhosa! Vivo dizendo isso pras pessoas e também me olham com cara torta! Tanta música boa pra gostar, pq insistir naquelas que reproduzem qualquer tipo de violência? Parabéns pelo trabalho!” (MULHER)

"eu sabia que tinha algo de estranho nessa msc, só nao sabia o que era..." (MULHER)
\end{abstract}

"Muita coisa precisa ser desconstruída nesse patriarcado nosso de cada dia... Ver movimentações nesse sentido é um alento! '” (MULHER)

"Depois da sua página, toda vez que escuto rádio na minha cabeça fica uma canetinha imaginária fazendo rabiscos" (MULHER)

"Idem! Tbm dei uma parada pra ler as letras que eu cantarolava por aí.Aaf! Repertório ficou escasso" (MULHER)

"Que horror!!!! Nunca tinha observado! Pouco ouço o cantor! Mas é um lixo inaceitável!!! Boicotar essa merda” (MULHER)

“obrigado demais pela indicação s2” (HOMEM)

"Prestei atenção na letra e traduzi pro meu filho de 11 anos que estava comigo no carro. Ele achou horrivel. Reforcei o erro deste tipo de açao, pedi pra que ele nao agisse dessa forma quando crescer... Pelo amor" (MULHER).

“também tem a belíssima opção de perdoar e seguir solteiro" (HOMEM).

Resposta do Arrumando Letras ao comentário acima: "Verdade, XXXX! vou até adicionar essa alternativa <3" (ARRUMANDO LETRAS).

"É interessante né, como é fácil quando as musicas que são machistas e enfim mas que não gostamos é de boa, mas quando chega uma música ou um artista que a gente gosta é sempre um baque, parabéns à página por esse choque" (HOMEM).

A contribuição das discussões nas mídias sociais pode colaborar bastante com a competência crítica em informação. Esta perspectiva é interessante para pensarmos em como despertar o gosto pela informação e colaborar com a formação da competência crítica em informação para a inclusão social e colaboração com uma sociedade mais democrática, equilibrada, justa e consciente.

\title{
8 CONSIDERAÇõES FINAIS
}

A partir dos resultados e discussões apresentados acima, aferimos que respondemos aos objetivos propostos inicialmente neste artigo. Quanto aos objetivos específicos, apresentamos as contribuições bibliográficas no que tange ao arcabouço teórico e conceitual sobre ética. Discutimos por intermédio das postagens da página Arrumando Letras, a dominação patriarcal e dominação masculina contra as mulheres presente nas músicas populares entre brasileiros e brasileiras. Utilizando a ARS, analisamos as postagens da página

\begin{tabular}{|c|c|c|c|c|c|}
\hline (C) RDBCI: Rev. Digit. Bibliotecon. Cienc. Inf. & Campinas, SP & v.16 & n. 3 & p. $317-337$ & set./dez. 2018 \\
\hline
\end{tabular}


e os tipos de publicação com maior visibilidade, bem como a interação e o discurso do público, sob a perspectiva da competência crítica em informação e refletimos como a esta é aplicada na página e se apresenta nas interações dos seguidores da mesma.

$\mathrm{O}$ conceito e as influências capitalistas e religiosas sobre a dominação patriarcal e como essas influências contribuíram e contribuem para a diferença de tratamento entre os gêneros foram refletidos e discutidos. Abordamos também, os conceitos de redes sociais online e mídias sociais, além do uso da página Arrumando Letras no Facebook como um importante espaço de militância e promoção de debate sobre respeito entre gêneros e herança de uma cultura patriarcal. Salientamos que, em momento algum, visamos estimular a sobreposição de um gênero em detrimento ao outro e sim, buscamos a igualdade de tratamento e equidade de direitos.

Assim, desejamos que cada vez mais a dominação patriarcal seja desconstruída, e seus danos na vida das mulheres erradicados à medida que o nosso protagonismo, bem como de outros gêneros, sejam cada vez mais representados, não só na Ciência da Informação, mas em outras ciências, na política, na educação e em diferentes contextos socioeconômicos e culturais.

\section{REFERÊNCIAS}

AMERICAN LIBRARY ASSOCIATION (ALA). Information literacy competency standards for higher education. Site da ACRL - Association of College \& Research Libraries. Chicago, 2010. Disponível em: <https://goo.gl/7b2Brn>. Acesso em: 20 set. 2017.

ARISTÓTELES. Ética a Nicômaco. São Paulo: Nova Cultural, 1991.

BARDIN, L. Análise de conteúdo. 3.ed. Lisboa: Edições 70, 2004.

BRASIL. Medida Provisória n ${ }^{\circ}$ 746, de 2016 (Reformulação Ensino Médio). Brasília, 2016. Disponível em: <http://www.congressonacional.leg.br/materias/medidas-provisorias//mpv/126992>. Acesso em: 11 Out. 2017.

BOURDIEU, P. Violência simbólica e lutas políticas. Meditações Pascalianas, 2001.

BEZERRA, A. Vigilância e filtragem de conteúdo nas redes digitais: desafios para a competência crítica em informação. In: ENCONTRO NACIONAL DE PESQUISA EM CIÊNCIA DA INFORMAÇÃO, 16., 2015, João Pessoa. Anais... João Pessoa: Universidade Federal da Paraíba, 2015. Disponível em: 〈http://bit.ly/2gKknBH>. Acesso em: 08 jan. 2017.

CAPURRO, R. Desafíos téoricos y prácticos de la ética intercultural de la información. In: FLORIDI, L. Ethics in the Infosphere. The Philosophers' Magazine, v. 6, p. 18-19, 2001. Disponível em: <http://www.capurro.de/paraiba.html>. Acesso em: 08 jan. 2017.

CARAN, G. M.; BIOLCHINI, J. C. A. Suporte social informacional mediado por grupos no

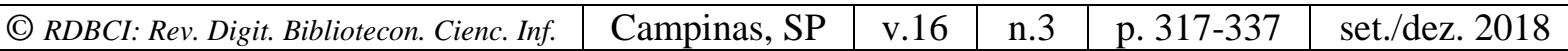


facebook: um estudo de caso. In: ENCONTRO NACIONAL DE PESQUISA EM CIÊNCIA DA INFORMAÇÃO, 16., João Pessoa, 26 a 30 de outubro de 2015. Anais... João Pessoa, 2015.

\section{CHAUÍ, M. Ética e violência. In: COLÓQUIO INTERLOCUÇÕES COM MARILENA}

CHAUI. Londrina/São Paulo, 1998.

COSTA, A. A. A. O movimento feminista no Brasil: dinâmicas de uma intervenção política. Revista Gênero, v.5, n. 2, p. 1-20, 2013.

CORREA, M. de V.; ROZADOS, H. B. F. Comportamento informacional em comunidades virtuais: um estudo netnográfico do grupo de interesses seer/ojs in brazil do facebook.

Biblionline, v. 12, n. 3, 2016. Disponível em: 〈http://www.brapci.ufpr.br/brapci/v/a/22145>. Acesso em: 24 Jun. 2017.

DOSSIÊ VIOLÊNCIA CONTRA AS MULHERES. Feminicídio. Instituto Patrícia Galvão, 2017. Disponível em:

<http://www.agenciapatriciagalvao.org.br/dossie/violencias/feminicidio/>. Acesso em: 14 Out. 2017.

DOTTA, S. Uso de uma mídia social como ambiente virtual de aprendizagem. Brazilian Symposium on Computers in Education, v. 1, n. 1, 2011. Disponível em: <http://brie.org/pub/index.php/sbie/article/view/1623>. Acesso em: 10 jun. 2017.

FREIRE, P. Educação Como Prática da Liberdade. Ed. Paz e Terra. Rio de Janeiro. 1967.

GASQUE, K. C. G. D. Arcabouço conceitual do letramento informacional. Ciência da Informação, Brasília, DF, (39) 3, 83-92, 2010.

GIL, A. C. Como elaborar projetos de pesquisa. 4. ed. São Paulo: Atlas, 2008.

GONZÁLEZ DE GÓMEZ, M. N. Desafios contemporâneos da ciência da informação: as questões éticas da informação. Anais do X Enancib, João Pessoa, 2009. Disponível em: $<$ http://enancib.ibict.br/index.php/enancib/xenancib/paper/viewFile/3133/2259>. Acesso em 14 de jun, 2017.

KANT, I. Fundamentação da Metafísica dos Costumes e outros escritos. São Paulo: Martin Claret, 2002.

KARAWEJCZYK, M. As suffragettes e a luta pelo voto feminino. História, 2013. Disponível em <http://amazonaws.com/academia.edu.documents/33267419/03suffragettes.pdf >. Acesso em 12 de jun, 2017.

MARTELETO, R. Análise de redes sóciais - aplicação nos estudos de transferência da informação. Ciência da Informação, Brasília, v. 30, n. 1, p. 71-81, 2001. Disponível em: <http://www.scielo.br/pdf/ci/v30n1/a09v30n1.pdf>. Acesso em: 10 Out. 2017. 
MARTELETO, R. M.; TOMAÉL, M. I. A metodologia de Análise de Redes Sociais (ARS). In: VALENTIM, M. L. P. V. (Org.). Métodos qualitativos de pesquisa em Ciência da Informação. São Paulo: Polis, 2005.

MARTELETO, R. Redes sociais, mediação e apropriação de informações: situando campos, objetos e conceitos na pesquisa em ciência da informação. Tendências da Pesquisa Brasileira em Ciência da Informação, v. 3, n. 1, p. 27-46, 2010. Disponível em: <http://www.brapci.ufpr.br/brapci/v/a/9339>. Acesso em: 24 Jun. 2017.

MATTOS, M. A. R. P. B. de. Ética profissional do bibliotecário. [s.n.]: Campinas, 1977.

OLIVEIRA, R. M. F. S. et al. O uso da rede social como prática de informação: um estudo no grupo 'mulher, me ajuda aqui' do facebook. Folha de Rosto, v. 3, 2017. Disponível em: <http://www.brapci.inf.br/v/a/28220>. Acesso em: 16 Maio 2018.

OMS (Organização Mundial da Saúde). Prevenção da violência sexual e da violência pelo parceiro íntimo contra a mulher: ação e produção de evidência, 2012. Disponível em: <http://apps.who.int/iris/bitstream/10665/44350/3/9789275716359_por.pdf?ua=1>. Acesso em: 14 Out. 2017.

PIVATTO, P. S. Ética da alteridade. In: OLIVEIRA, M. A. de (Org.). Correntes fundamentais da ética contemporânea. 2 ed. Petrópolis: Vozes, 2000.

PIZA, E. Identidade feminina e problemas de ensino-aprendizagem em "A mulher escondida na professora: uma leitura psicopedagógica do ser mulher, da corporalidade e da aprendizagem". Projeto História: Revista do Programa de Estudos Pós-Graduados de História, v. 11, 1994.

PIZARRO, D. C. Ética profissional do bibliotecário atuante no segmento empresarial em Santa Catarina. Florianópolis. 2010. 213 f. Dissertação (Mestrado em Ciência da Informação) - Universidade Federal de Santa Catarina, Programa de Pós-Graduação em Ciência da Informação, 2010.

RIBEIRO, D. Para além da biologia: Beauvoir e a refutação do sexismo biológico. Sapere Aude-Revista de Filosofia, v. 4, n. 7, p. 506-509, 2013. Disponível em <http://periodicos.pucminas.br/index.php/SapereAude/article/view/5565> Acesso em: 12 de jun, 2017.

ROSADO-NUNES, M. J. Teologia feminista e a crítica da razão religiosa patriarcal: entrevista com Ivone Gebara. Revista Estudos Feministas, v. 14, n. 1, p. 294-304, 2006.

SÁNCHEZ-VÁZQUEZ, A. Ética. 12 ed. Rio de Janeiro: Civilização Brasileira, 1975.

SÁNCHEZ VÁZQUEZ, A. Ética. Rio de Janeiro: Civilização Brasileira, 2004.

SANTOS, P. W. Q.; ALBUQUERQUE, J. P. S. Redes sociais online como espaços de memória: uma visão a partir da página "Recife de antigamente". Biblionline, v. 13, n. 3, 2017.

SANTOS NETO, J. O. A.; ALMEIDA JÚNIOR, O. F. Bibliotecas universitárias das

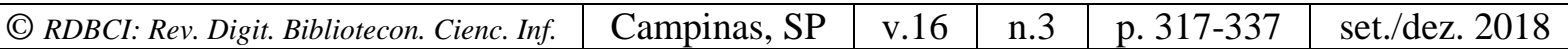


instituições estaduais de ensino superior paranaenses e a mediação da informação no facebook. Revista Digital de Biblioteconomia \& Ciência da Informação, v. 15, n. 2, 2017. Disponível em: <http://www.brapci.inf.br/v/a/28002>. Acesso em: 16 Maio 2018.

SILVA, R. C. et al. A competência em informação e o comportamento informacional dos usuários de bibliotecas híbridas: um estudo comparativo no brasil e na escócia. Informação \& Informação, v. 23, n. 1, 2018. Disponível em: <http://www.brapci.inf.br/v/a/29574>. Acesso em: 16 Maio 2018.

SOUZA, T. M. dos S. Patriarcado e capitalismo: uma relação simbiótica. Temporalis, v.15, n. 30, p. 475-494, 2016. Disponível em: <http://negrem.blogspot.com.br/2016/02/patriarcadoe-capitalismo-uma-relacao.html>. Acesso em: 13 de jun, 2017.

TUGENDHAT, E. Lições sobre ética. 5 ed. Petrópolis: Vozes, 1996.

VINHAL, G. Página no Facebook 'arruma' letras machistas de canções e viraliza na web. Diário de Pernambuco, 2017. Disponível em:

<http://www.diariodepernambuco.com.br/app/noticia/brasil/2017/03/27/interna_brasil,69614 0/pagina-no-facebook-arruma-letras-machistas-de-cancoes-e-viraliza-na.shtml> Acesso em: 14 jun. 2017.

VITORINO, E. V.; PIANTOLA, D. Competência informacional - bases históricas e conceituais: construindo significados. Ciência da Informação, Brasília, DF, v. 38, n. 3, p. 130-141, 2009. Disponível em: <http://www.scielo.br/pdf/ci/v38n3/v38n3a09.pdf>. Acesso em: 25 nov. 2015.

WAISELFISZ, J. J. Mapa da Violência 2015: Homicídio de Mulheres no Brasil, 2015. (Flacso/OPAS-OMS/ONU Mulheres/SPM, 2015). Disponível em: <https://apublica.org/wpcontent/uploads/2016/03/MapaViolencia_2015_mulheres.pdf>. Acesso em 14 Out. 2017.

ZITKOSKI, J. J.; TROMBETTA, S. Ética e direitos humanos: um olhar da Filosofia sobre os desafios da educação contemporânea. In: HAMMES, L. J.; SELAU, B. (Orgs.) Educação, como estás? Debates na trama de temas emergentes. Lajeado: UNIVATES, 2011.
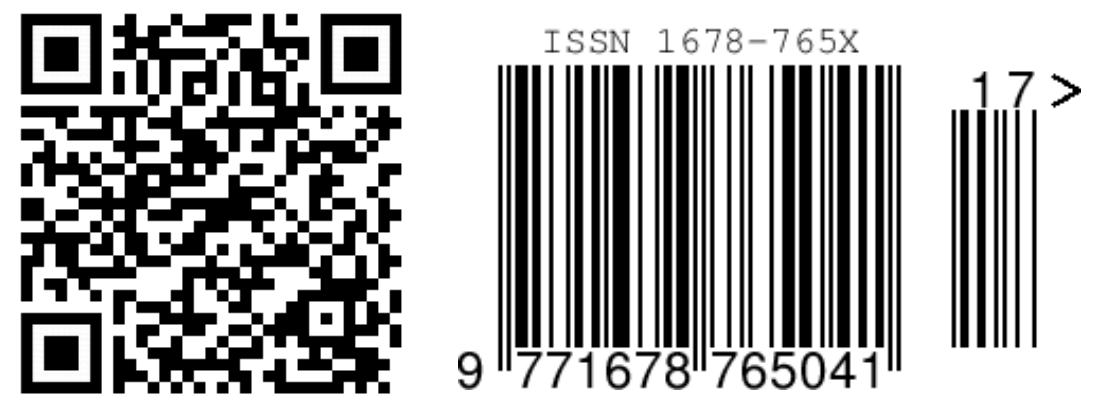

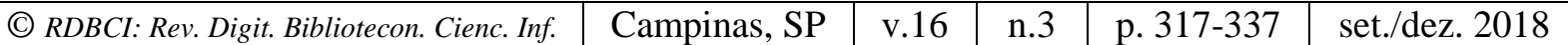

